
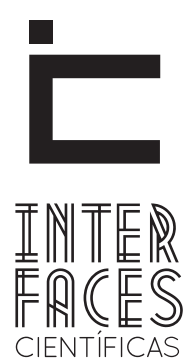

EDUCAÇÃO

ISSN IMPRESSO 2316-333X

ISSN ELETRÔNICO 2316-3828

DOI 10.17564/2316-3828.2015v3n3p55-65

\title{
O ÓCIO COMO TEMPO LIVRE, E A SUA CONTRIBUICÇÃO PEDAGÓGICA PARA A EDUCAÇÃO
}

Marlton Fontes Mota ${ }^{1}$

Dinamara Garcia Feldens ${ }^{3}$

\section{RESUMO}

O ócio, ao longo da história, vivenciou a deturpação de conceitos, vinculando-se à ideia de ociosidade, mesmo acolhido na concepção de ócio criativo. Ao pretender elucidar as suas diversas diferenças conceituais, os estudiosos passaram a perceber o ócio como um processo contínuo de aprendizagem, incorporado ao desenvolvimento de atitudes, valores, e competências, passando a ser reconhecido como parte integrante da educação, pontuando o fato de que a melhor fonte do ócio está no próprio indivíduo. 0 presente artigo pretende demonstrar que a educação tornou-se uma das grandes responsáveis em inspirar a mudança de paradigma sobre a experiência do ócio, isto, com a preocupação de educar no tempo livre e para o tempo livre.

\section{PALAVRAS-CHAVE}

Ócio. Educação. Indivíduo. Autonomia. Experiência. 


\section{ABSTRACT}

Idleness, throughout history, experienced the misrepresentation of concepts, linking it to the idea of idleness even welcomed in designing creative leisure. When aiming to elucidate its various conceptual differences, scholars began to realize idleness as a continuous learning process, incorporated into the development of attitudes, values, and skills, becoming recognized as an integral part of education, highlighting the fact that the best source of enter-

\section{RESUMEN}

La ociosidad, a lo largo de la historia, experimentado latergiversación de conceptos, vinculándola a laidea de laociosidad, incluso diolabienvenidaeneldiseño de ociocreativo. Cuandoel objetivo de esclarecer sus diversas diferencias conceptuales, los estudiosos comenzaron a darsecuenta de laociosidad como unproceso de aprendizaje continuo, incorporado eneldesarrollo de actitudes, valores y habilidades, llegando a ser reconocida como una parte integral de laeducación, destacando elhecho de que elmejorfuente de entre- tainment is the individual himself. This article argues that education has become one of the main culprits in inspiring the paradigm shift on the experience of leisure, this, in the interest of educating the free time and free time.

\section{KEYWORDS}

Leisure. Education. Individual. Autonomy. Axperience. tenimiento es el individuo mismo. En este artículo se sostiene que laeducación se ha convertido en uno de losprincipalesculpables de inspirar el cambio de paradigma enlaexperiencia de ocio, es decir, enelinterés de laeducacióndeltiempo libre y eltiempo libre.

\section{PALABRAS CLAVE}

Ocio. Educación. Individuales. Autonomía. La Experiencia. 


\section{INTRODUÇ̃̃̃O}

Enquadrar o ócio como tempo livre é, inicialmente pressupor a busca pelo criativo, e não somente pretender justificar o tempo dedicado ao (não) trabalho para que não transpareça que foi destinado à contemplação da preguiça. Da mesma forma, ao condicionar o ócio, enquanto possibilidade de experiência subjetiva, dotando de mais sentido e autonomia a existência do sujeito, seria outra forma de contrapor o trabalho, mas, não poderia se resumir a isto sem efetivamente dissociar o homem da sua capacidade de criação, de aceitação e de ser introspecto.

Ainda que se justifique como sendo decorrente do 'tempo livre', denominação que originalmente se filia à ideia pré-concebida do ócio; é perceptível o fato de que, assim como a relação do individuo com ele mesmo se intensificou com o passar do tempo, independente da atividade (não) realizada, a ideia da pedagogia para o tempo livre percorreu o mesmo caminho, pois, se compatibiliza com a formação de valores, com o pensamento crítico e com a participação social; parâmetros estes que já são sinais de evolução na experiência do ócio e não o delimitam, pois, a sua vivência tem contribuído para a formação do aluno, dentro e fora das salas de aula.

É patente a responsabilidade das instituições (família, educação, trabalho etc.) nesse processo, pois, ao permitir a aplicação do tempo livre pelo aluno, de forma autônoma, se estará proporcionando o clima apropriado para consolidar a contribuição formativa do ócio para o próprio indivíduo, que será o protagonista a atuar como veículo de experimentação da vida.

Sem dúvidas, a educação tornou-se uma das grandes responsáveis em inspirar a mudança de paradigma sobre a experiência do ócio, isto, com a preocupação de educar no tempo livre e para o tempo livre, termos estes que, apesar de se demonstrarem em conceitos distintos, convergem para preparar o indiví- duo a um ócio pleno de possibilidades, demonstrando que o ócio, na sua abordagem de 'tempo livre', preconiza ações que devem decorrer do indivíduo para si mesmo, e que lhe permita alcançar suas próprias mudanças, suas experimentações, ampliando seu território de conhecimentos.

Os estudiosos do tema insistem em prescrever sobre a busca de um ócio que 'trabalhe' a liberdade de escolha, permitindo a gestão autônoma das atividades realizadas pelo indivíduo sem incorrer no risco de manter institucionalizados o lazer, a criatividade, a reflexão e a própria singularidade, pois, a fim de otimizar o tempo de não atividade, as instituições, inclusive a escola, prescrevem atitudes, valores e signos que se amoldam ao interesse do mercado. 0 estímulo ao ócio, o desenvolvimento de um plano de atuação educativa sobre o tempo livre, uma melhor distribuição e aproveitamento desse tempo, deve também, ser tarefa conjunta das instituições educativas, dentre elas, a escola e a família.

\section{0 ÓCIO E A EDUCAÇ̃̃: BREVES CONSIDERACÕES}

Para Trilla e Puig (2004, p. 22) o sentido de ócio, dos termos afins e complementares, evoluiu com o tempo até mudar radicalmente de conteúdo, e cada momento histórico justifica a mistura de interpretações políticas, morais, religiosas e econômicas vinculadas à concepção de ócio, a saber:

\footnotetext{
Para os gregos, o tema do ócio, implicitamente, como em muitas outras vivências culturais, ou explicitamente, como nas reflexões de Aristóteles, constitui um tema importante na configuração de seu ideal humano. [...] Assim, o ócio grego é o oposto ao trabalho, implica libertar-se da necessidade do trabalho e assim dispor de tempo. [...] Portanto, o ócio é uma característica que define o homem livre, ou seja, o ócio não se baseia numa determinada quantidade de tempo livre [...]. O ócio se opõe à ocupação, especialmente quando esta implica alguma atividade de ócio que o simples fato de realizá-la.
} 
A ideia de aprimorar a liberdade de pensamento, à égide de uma educação que promova no indivíduo a motivação inventiva e a própria experimentação, exortando-lhe o poder de criação, de subjetividade e a sua conectividade com o mundo e que possa conceber a libertação de conceitos institucionalizados, quer seja na atividade laboral ou mesmo na própria instituição educacional, tende a criar possibilidades para que o ócio contribua como atividade formativa para o estudante, promovendo a sua própria importância para o processo de educação.

Tal raciocínio é acompanhado pelo professor Clerton de Oliveira (2005), num entendimento de que a "educação deve estar preparada para oportunizar ao indivíduo uma autoavaliação dos conceitos que permeiam a sua própria existência”, sendo que apesar de trabalhar o aprimoramento do tempo livre num entendimento vinculado à criatividade, essa mesma conduta invoca a formação do ócio de maneira ampla, vinculando essa responsabilidade, também, ao papel da instituição educacional, assim prediz o autor:

Assim, a forma de sentir, pensar, agir e estabelecer o tempo livre segue padrões culturais que determinam como ser e atuar diante dele. Nesse âmbito, apesar de todo reconhecimento constitucional para o tempo livre, a falta de uma educação para o uso do ócio, termina por minar a criatividade, transformando o homem em uma mera extensão de sua vida laboral e o ócio em um reflexo do trabalho.

Torna-se emergente uma educação não só para perceber os meandros do trabalho, mas também para os mais diversos e possíveis ócios, significa ensinar como se evita a alienação que pode ser provocada pelo tempo vazio que é tão perigoso quanto à alienação derivada do trabalho. (OLIVEIRA, 2005, p. 1).

Percebe-se que a preocupação com o ócio passa agora a assumir um papel mais focado em reconhecer a sua parcela contributiva para a formação do indivíduo, tornando-se determinante, tanto para a extensão da sua vida profissional, quanto para o seu próprio livre agir e pensar, numa conotação maior do que propulsionar a criatividade, mas, extraindo-lhe a própria criação individual.
De La Torre (2008, p. 28) disserta que "para potencializar a criatividade, não necessariamente se extrai do conteúdo disciplinar, mas, daquilo que lhe seria equivalente, qual seja, o conhecimento dos componentes da própria criatividade", e de acordo com o seu pensamento:

Implica promover, principalmente, atitudes criadoras, dinamizando as potencialidades individuais, favorecendo a originalidade, a apreciação do novo, a inventividade, a expressão individual, a curiosidade e a sensibilidade frente aos problemas, a receptividade no tocante à novas idéias, à percepção e à auto-direção. (TORRE, 2008, p. 28).

Nesse contexto tratado pelos estudiosos do tema, o indivíduo tem sido parte importante na contribuição positiva para o futuro da humanidade, e a escola poderá sim, promover a experiência do ócio como atividade contributiva para a formação do aluno, quer seja na união de conhecimentos, proposta por alguns dos autores, ou mesmo permitindo maior liberdade para o seu aluno poder vivenciar essa experiência.

Veloso Brasileiro e outros autores (2011, p. 2) se manifestam em afirmar que "a escola parece compactuar com a concepção utilitarista”, preocupando-se em prover os indivíduos de elementos que possibilite ter sucesso no mundo profissional, sem ensinar a valorizar a si e aos outros, ajudando-os a descobrirem seus talentos, a desenvolver a sua criatividade e a respeitar o direito de ser e de ter limites:

A transformação de tempo livre em ócio não é tarefa espontânea e o modelo de gerações passadas não nos servem mais. Um tipo de ócio tem a ver com um tipo de educação e, consequentemente, uma maneira de entender a educação desenvolve um tipo de ócio diferente. Ócio e educação são essenciais ao desenvolvimento humano. Desse modo, a educação formal é a base para se ascender ao ócio cultural e elevar a capacidade para aprender; para nos comunicar e para pensar. A educação formal, portanto, incrementa as possibilidades de ócio e melhora as possibilidades de satisfação vital. (BRASILEIRO, 2011, p. 2).

O ócio, pelo que se percebe, é imprescindível para o cultivo de ideias, e a experiência do ócio, ainda que 
inserto na subjetividade do aluno, se elevado à condição de atividade formativa pela educação, propõe-se a provocar, inspirar e intuir o desenvolvimento do autoconhecimento como fonte de liberdade e crescimento do indivíduo, potencializando a sua participação social.

\section{A ATIVIDADE PEDAGÓGICA DO ÓCIO}

A ideia do avanço das relações humanas com o capital, quando são ofertados ao indivíduo avanços tecnológicos, industriais e culturais, têm efetivamente proporcionado o crescimento de problemas socioeducativos, pois, a depender da escala social a que pertence o indivíduo, o esforço físico e intelectual é ainda mais exigido, assim como a sua participação nesse processo de humanização das ações.

Para alguns estudiosos do tema o ócio se resume a um potencial de introspecção do indivíduo, sendo utilizado como forma de expressão do ser humano e ao mesmo tempo se consolida como uma forma dinâmica de identificação deste com o mundo. E é dessa integração do indivíduo com o mundo, que Rodhen (2009, p. 1) atribui ao ócio o caráter humanista, assim descrevendo:

Portanto, a experiência de ócio é também o intercâmbio do Ser com o mundo. Neste processo, o sujeito muda e muda o seu entorno, realizando naturalmente um exercício de aprendizagem espontânea. [...] Neste contexto, o ócio humanista entendido como fenômeno psicossocial e âmbito da vida, apresenta-se como mais um caminho capaz de aproximar o homem de seu projeto existencial. Acreditamos que, numa perspectiva humanista, o ócio pode beneficiar o homem em muitos aspectos: autodescoberta, desenvolvimento psicológico e social, saúde e qualidade de vida.

É invariável que o fator tempo, estando ligado diretamente ao conceito do ócio, sofreu grandes e profundas transformações, conforme já observado, influenciando diretamente sobre as questões sociais e econômicas, endereçando ao centro dessas transformações, o indivíduo.
Nesse pensamento, Silva e outros autores (2006, p. 3) entendem que:

\begin{abstract}
Ao evidenciar as possibilidades de intervenção pedagógica via relação - lazer e educação, nas quais ressalta a importância do lazer como produto cultural e industrial, gerador de empregos, a educação para o lazer deverá sofrer adaptações às necessidades locais, levando em consideração os diferentes sistemas sociais, culturais e econômicos, como também, ser um processo de aprendizado contínuo, que incorpora o desenvolvimento de atitudes, valores, conhecimentos e aptidões.
\end{abstract}

Extraindo-se a ideia colacionada na 'Carta Internacional do Ócio' ou 'Carta Internacional de Educação para o Lazer” (1998, p. 5), que se trata de um documento internacional para a educação do ócio, e que foi criada, reunindo a opinião de um grande número de pessoas e instituições de várias partes do mundo, é possível confirmar sobre a importância do ócio para a humanidade:

4.3. A educação do ócio é um processo contínuo de aprendizagem que incorpora o desenvolvimento de atitudes, valores, conhecimentos, competências e recursos de ócio.

4.4. Os sistemas de educação formal e não formal têm uma posição privilegiada para implementar a educação do ócio e animar e facilitar a participação das pessoas neste processo.

4.5. A educação do ócio foi reconhecida como parte integrante da educação e, embora genericamente não tenha sido posta em prática, é percebida como uma parte importante do processo de socialização, na qual, diferentes agentes têm um papel fundamental. Esta Carta centra-se na escola, na comunidade e na formação de profissionais.

O desenvolvimento técnico-industrial, diante da discussão abordada, adicionou na escola uma variedade de métodos pedagógicos, que invariavelmente produziram mais controle sobre o indivíduo, e sua influência se conduzia para ampliar a submissão do homem pela regulação do tempo e do espaço, visando exercer controle, inclusive, sobre o seu tempo livre.

Ainda, discutindo a respeito do tema ora abordado, Wogel (2007, p. 86) esclarece que "na escola, 
faz-se o que é necessário e não o que é desejável, ou seja, os desejos do indivíduo, as suas realizações pessoais são subjugadas ante as obrigações que devem ser cumpridas", e isto traz à superfície da discussão o ócio, surgindo uma interrogação sobre como ele pode ser educativo ou fazer do ócio uma ação educativa. Enfim, Wogel (2007, p. 86) afirma que:

O ócio pode tornar-se educativo, à medida que se valoriza alguns aspectos da vida, especialmente, de si mesmo, pois, no ócio, a pessoa é realmente sujeita do seu aprendizado, pois parte de si a vontade de aprender e não da necessidade de outro. [...] a escola carece da reflexão sobre este valor humano e ainda mais quando impossibilita este valor.

De fato, se percebe nos destaques, ora abordados, que a educação se tornou uma das grandes responsáveis por inspirar a mudança de paradigma sobre a experiência do ócio, isto como o objeto da pedagogia, pois, de acordo com os autores, anteriormente comentados, está muito vinculada à idéia de educar no tempo livre.

Novamente, Trilla e Puig (2004, p. 74) se pronunciam ao inferir que, "educar no tempo livre e educar para o tempo livre são termos que não se excluem, apesar de possuírem significados distintos", e isto provoca a pedagogia, que a partir dessa discussão deve assumir que a sua ação deverá, também, acontecer 'mediante' o ócio, devendo despontar na realização de uma atividade ou de uma atitude no educando, englobando ao mesmo tempo, ambas as perspectivas.

A ideia destacada acima importa a ampliação do objetivo da pedagogia do ócio, que passa a agir com a subjetividade (autonomia) do indivíduo, preconizando a aplicação do tempo livre, aquele decorrente da (não) realização de uma atividade, para que almeje a libertação do autoconhecimento e emancipe o sujeito dos sentimentos e dos objetivos da comunidade, para que a verdadeira construção comece nele próprio.

Nessa seara, a 'pedagogia do ócio' tende a ser aplicada como um instrumento para a ampliação e inte- gração do objeto das disciplinas pedagógicas, porém, a ideia é tangenciada para absorver aquela que é chamada de educação para o tempo livre.

$E$ a respeito do tema, cabe suscitar o pensamento de Trilla e Puig (2000, p. 17), os quais destacam o fato de que "a pedagogia universitária, até recentemente, não, se preocupava muito pouco em ter entre seus objetos aquele constituído pelo setor educativo do tempo livre e da animação sociocultural”.

Para os autores acima destacados (2000, p. 17), a situação está mudando, pois, "a pedagogia se mostra cada vez mais disposta a incorporar a seus planos de estudo, suas linhas de pesquisa e tarefas de formação profissional, âmbitos de intervenção educativa que ficam fora do convencional", e mesmo com a conotação de 'fora do convencional', concluem que "há de se admitir que o ócio faz parte do cotidiano do indivíduo, quer seja intra, ou extra muros escolares".

As atuais críticas ao movimento educacional se direcionam a pedagogia aplicada no equacionamento de abordagens que tendem a formatar o indivíduo, numa preocupação exclusiva de manter um aparato avaliativo e a adequação ao interesse do mercado de trabalho, e para Trilla e Puig (2004, p. 74), "uma pessoa prepara-se para viver o ócio, fundamentalmente, por meio do próprio ócio".

Inegavelmente, o sistema capitalista provocou o emprego de abordagens tecnológicas na área educacional, mas, o que se percebe na prática é o seu uso para estabelecer critérios e indicadores de eficiência da entidade educacional, que na verdade, evidenciam a aplicação de um controle excessivo sobre os aspectos da vida escolar, que segundo os especialistas no tema, desfigura o real papel da educação.

Discute-se se o sistema educativo deveria desempenhar um papel diferente daquele que promove hoje, que é o de preparar o indivíduo tão somente para desempenhar um rentável papel na sociedade, e para 
Trilla e Puig (2004, p. 77): “a primeira tarefa da pedagogia do ócio não é distrair e divertir, deve sim colaborar com o indivíduo para que aprenda a se divertir melhor, devendo respeita a autonomia do sujeito", que, de forma coerente, deve "decidir livremente a atividade a ser realizada, e a forma como deverá executá-la”. E o estimulo à contemplação, independente da área científica e de pesquisa aplicadas, conforme raciocínio dos autores, "poderá ser um caminho a ser utilizado pela escola para possibilitar ao aluno a descoberta do prazer, e a melhor aplicação do conhecimento de si”.

\section{FORMAS DE APLICAÇÃO DO ÓCIO NA EDUCAÇÃO}

Inicialmente é preciso destacar sobre o real objetivo da experiência do ócio na educação, para se permitir que dele decorra uma atitude independente e liberal, que "justificam perfis reconhecidamente inerentes às pessoas criadoras", de acordo com De La Torre (2008, p. 35), pois, se direcionado apenas à preocupação com o mercado profissional, o objetivo traçado pela educação estará limitado à vocação ao capitalismo, contrariando a ideia do autor, que acredita no fato de que os movimentos educativos caminham para estimular a independência perceptiva, e justifica que: “[...] a liberdade externa, fictícia, se tornará interna, com a liberação de todas as possibilidades criadoras existentes em nós" (TORRE, 2008, p. 35).

De La Torre (2008, p. 36) ainda persiste na proposta de que "a educação na liberdade possibilitaria o estímulo à fantasia e a espontaneidade", e sendo a autossuficiência uma característica marcante dos talentos criadores, entende o autor que a educação pode potencializá-la em seus educandos.

Da 'Carta Internacional do Ócio' (1998, p. 5), documento direcionado para a educação do ócio, é possível observar que o objetivo geral da Educação do Ócio é o de propiciar ao aluno a busca por uma melhor qualidade de vida. A Carta ainda define que essa busca por uma melhor qualidade de vida, por meio da expe- riência do ócio, é viável; onde a composição se une, quer seja de fatores pessoais, sociais, emocionais ou mesmo intelectual, todos, para desenvolvimento de conhecimentos e de competências. Nesse ínterim, a Carta traça os seguintes princípios e estratégias para a Educação do Ócio nas escolas:

\begin{abstract}
2.2.1. Identificar o conteúdo de ócio que existe em cada matéria do currículo e nas atividades extracurriculares. 2.2.2. Incluir matérias que sejam apropriadas e relevantes para o estudo do ócio, direta e indiretamente. Cada matéria deveria ser impregnada de conteúdos de ócio. 2.2.3. Promover a incorporação do tema do ócio em todas as atividades educativas e culturais, dentro e fora da escola.
\end{abstract}

O objetivo celebrado no referido documento se perfaz em tentar promover a Educação para o Ócio, devendo ocorrer de forma continuada, sem incutir excessos de atividades nem propagar a não realização destas; o que se percebe é que há uma busca pelo equilíbrio entre ambas para que se vinculem, ainda que de forma autotélica, mas, que inspirem o aluno a se compatibilizar, enquanto ganha em autoconhecimento, reflexão e participação social.

Ao quebrantar o conceito do ócio na educação, os atuais pensadores do tema se colocam na posição de entendimento de que o ócio não se propõe a melhorar a 'engrenagem' do homem, mas, que num pensamento que alie a subjetividade, a sua autonomia nas escolhas à concepção social, possa permitir-lhe um olhar sobre o espaço delimitado para si, encontrando a si mesmo nesse contexto de supervalorização da função social, e a Carta Internacional do Ócio (1998, p. 3) identifica o tempo livre como um direito básico do ser humano, assim predito no seu artigo $1^{\circ}$ :

Artigo 1: Tempo Livre é um direito básico do ser humano. Supõe-se, por isto, que os governantes tenham a obrigação de reconhecer e proteger este direito e os cidadãos de respeitar o direito dos outros. Donde, este direito não pode ser negado a ninguém por qualquer motivo: credo, raça, sexo, religião, incapacidade física ou condição econômica. 
Ainda que se questione a forma com que a pedagogia do ócio é aplicada nas instituições educacionais, à luz dos posicionamentos, ora demonstrados, não se pode afastar o fato de que o ócio na educação tem contribuído para a formação do indivíduo, quer seja de forma lúdica ou mesmo como resultado de interações do aluno ao mundo, fora dos muros escolares, ou de participações em projetos extraclasses.

Aplicando-se exemplos práticos sobre o ócio na educação, se extrai o pensamento de Trilla e Puig (2004, p. 60), que enfatizam sobre o reconhecimento do valor formativo da atividade lúdica como um fator de grande interesse para a pedagogia do ócio, aquilo que os autores denominam de "pedagogia da brincadeira":

0 reconhecimento de que a brincadeira, por si mesma, e sem estar necessariamente instrumentalizada com conteúdos pedagógicos, é uma atividade insubstituível do desenvolvimento da criança constitui outro dos fatores de potencialização da pedagogia do ócio. A brincadeira não é a única atividade, mas uma das mais paradigmáticas do tempo livre. Portanto, o reconhecimento do valor formativo da atividade lúdica não podia fazer outra coisa senão reforçar a reflexão pedagógica sobre o tempo livre.

A função lúdica na educação infantil é vista com naturalidade por grande parte dos estudiosos e pesquisadores do tema, pois, para eles a criança brinca aprendendo ou aprende brincando; e isto, notadamente demonstra que a experiência do ócio como meio instrutivo e educativo concebe uma forma de desenvolvimento no aluno, e para isso, não se verifica a existência de relação conflituosa entre o 'horário' de aprender e o 'horário' de brincar.

Ferreira (2010), nesse processo de contribuição para a experiência do ócio, propõe a inserção da arte na educação, como sinônimo de valorização, socialização e como expressão de sentimentos, que auxilia e harmoniza a desenvolvimento de habilidades:

A arte na educação tem como finalidade explorar e desenvolver as potencialidades do aluno, uma vez que ela abre portas para um caminho que vai além de uma disciplina no currículo escolar. 0 aluno torna-se mais sensível quando tem a arte como algo significativo em sua educação. E cabe ao professor a tarefa de levá-lo a novas descobertas, buscar promover a conscientização e a efetiva participação no processo de vida e, também, valorizar as relações na interação e na integração entre o conhecimento e as experiências do aluno. (FERREIRA, 2010, p. 22).

De forma mais alusiva ao tema, Ferreira (2010, p. 72) "propõe a dramatização, na qual o educador poderá iniciar um trabalho de artes cênicas, utilizando como recurso as situações vividas no cotidiano do aluno". A ideia, sem sombra de dúvidas, fomenta a espontaneidade e a criação, ampliando o mundo de respostas, tanto do docente, quanto do aluno, e acima de tudo ajusta o sentimento de respeito à individualidade e a liberdade de expressão. Certamente, a inserção da arte na educação aumentaria a potência do aluno, fazendo com que todos os seus sentidos se aprimorassem, tornando-os mais perceptivos e sensíveis, inclusive para os problemas do mundo.

Percebe-se que a experiência do ócio como tempo livre possibilita a formação de um ambiente escolar mais criativo, que representa uma tarefa multiplicadora para os envolvidos, provocando a manifestação em perguntas e respostas, estimulando atividades imaginativas e a liberdade de expressão.

Na sua proposta, Wogel (2007, p. 133) afirma sobre uma maior e mais ampla dimensionalidade do ócio, que consistiria nas "dimensões lúdicas, criativas, festivas e ecológicas”, e expõe o seu pensamento, justificando-as pelo fato de que "a dimensão lúdica desenvolve o jogo e a brincadeira”. E ao tratar de dimensão, o referido autor destaca que "a dimensão ambiental-ecológica refere-se ao encontro gratificante com o entorno, os ambientes e a natureza", e afirma que:

É difícil deixar de associar educação do ócio e amor à natureza, levando a crer que o aproveitamento do tempo livre, fora dos muros escolares, invoca a dimensão criativa, a um incentivo ao conhecimento e à manifes- 
tação das artes, tanto musicais-literárias, quanto plásticas e aplicadas. (WOGEL, 2007, p. 133).

Importa destacar que a escola, com base nos comentários acima, necessariamente precisa promover o alinhamento de conceitos e objetivos, para enfim, por meio da experiência do ócio como tempo livre, contribuir ainda mais para a formação do seu aluno, pois, apesar do fato de que a reprodução de conhecimentos seria o objetivo destacado, o estímulo à arte e o respeito ao cotidiano do indivíduo, de forma positiva, tende a produzir maior conscientização e interação entre as experiências do aluno e a sua educação formal, sendo um elo que tem como pilar a sensibilidade.

\section{CONSIDERACÕES FINAIS}

Invariável o fato de que a experiência do ócio foi inicialmente definida como sendo uma forma de autoconhecimento, e tal pressuposto foi a fonte de inspiração do período grego antigo, tendo como função basilar o contraponto ao trabalho, afinal, a preocupação dos eruditos à época era fomentar a introspecção, o elo contemplativo que unia o homem a si mesmo.

É pontual destacar sobre a importância da educação em inspirar a mudança de paradigma sobre a experiência do ócio, aduzindo que esta deve ser direcionada em também educar no tempo livre e para o tempo livre, termos estes que consolidaram para o indivíduo o ócio pleno de possibilidades, fazendo com que se perceba que o processo do conhecimento é continuativo, inclusive fora da própria escola.

De acordo com a 'Carta Internacional do Ócio' (1998, p. 4), também conhecida como 'Carta Internacional de educação para o lazer’, prevê-se que a “meta geral da educação para o lazer é ajudar estudantes em seus diversos níveis a alcançarem uma qualidade de vida desejável através do lazer". Isto pode ser obtido pelo desenvolvimento e promoção de valores, atitudes, conhecimento e aptidões de lazer por meio do desenvolvimento pessoal, social, físico, emocional e intelectual, que por sua vez, terá um impacto na família, na comunidade e na sociedade como um todo. 0 referido documento provoca a reflexão sobre as possibilidades práticas de ócio, tais como: cultural, esportiva, recreativa, turística, a partir da sua concepção e valorização por meio do melhor uso do tempo.

O papel da educação nesse processo se demonstra como sendo o de permitir a aplicação das diversas possibilidades do ócio, já que atua como veículo de informação e possui condições de compatibilizar tais institutos. Para De La Torre (2008, p. 35) é possível condicionar a independência perceptiva, da seguinte forma:

\begin{abstract}
Não devemos ter medo de formar na independência de pensamento. A educação não deve estar orientada para manter um sistema ou estrutura social determinados, mas, sim para formar homens íntegros que se auto-realizem na sociedade na qual eles têm de viver.
\end{abstract}

Em idêntica importância, a pedagogia do ócio se relaciona com a realidade social, econômica e demográfica, que são fatores externos à própria pedagogia, mas, tais circunstâncias propiciaram a diversidade de ações educativas direcionadas para a melhor utilização do chamado 'tempo livre', que, por sua vez, é uma consequência das transformações urbanas, que ditam o ritmo da sociedade.

Ainda que se questione a forma com que a pedagogia do ócio é aplicada nas instituições educacionais, à luz dos posicionamentos, ora demonstrados, não se pode afastar o fato de que o ócio na educação tem contribuído para a formação do indivíduo, quer seja de forma lúdica, ou mesmo como resultado de interações do aluno ao mundo, fora dos muros escolares, ou de participações em projetos extraclasses.

Reitere-se o fato de que o papel da escola nesse processo é de fundamental importância, pois, conforme aqui destacado, alia a formação intelectual à formação moral, ética e cívica dos alunos, e isto envolve, também, a sociedade que a circula; por essas razões, 
a escola se torna uma instituição essencial nesse procedimento de reestruturação de valores e conhecimentos, no sentido de melhor direcionar ou ainda de permitir a formação da experiência do ócio.

\section{REFERÊNCIAS}

CLERTON MARTINS, José. Educação para o ócio é educar também para a vida. Diário do Nordeste. 2011. Entrevista. Disponível em: <http://diariodonordeste. globo.com/materia.asp?codigo $=1010290>$. Acesso em: 2 jun. 2014.

DE LA TORRE, Saturnino de La. Criatividade Aplicada: recursos para uma formação criativa. CARBALLAL, Carmen (Trad.). São Paulo: Madras, 2008.

FERREIRA, Aurora. Arte, escola e inclusão - atividades artísticas para trabalhar com diferentes grupos. Petrópolis, RJ: Vozes, 2010.

RHODEN, leda. O ócio como experiência subjetiva: contribuições da psicologia do ócio. Revista mal estar e subjetividade. 2009. Disponível em: <http:// redalyc.uaemex.mx/src/inicio/ArtPdfRed.jsp?iC$v e=27115487008>$. Acesso em: 6 maio 2014 .

SILVA, Renata Laudares. RAPHAEL, Maria Luiza. SANTOS, Fernanda Silva dos. Carta Internacional de Educação para o lazer como ferramenta de intervenção pedagógica efetiva no campo do saber. Revista pensar a prática. 2006. v.9. Disponível em: <http://www.revistas.ufg.br/index.php/fef/article/view/128/1489>. Acesso em: 13 jun. 2014
TRILLA, Jaume; PUIG, Josep Maria. A pedagogia do ócio. Valério Campos (trad). 2.ed. Porto Alegre: Artmed, 2004.

VELOSO BRASILEIRO, Fabiana. OLIVEIRA MARTINS, José Clerton. Educação para o ócio a escola contemporânea: algumas reflexões. 2011. Apresentação oral em GT. Disponível em: <http://www.encontro2011. abrapso.org.br/trabalho/view?ID_TRABALHO=3392>. Acesso em: 10 maio 2014.

WOGEL, Livio dos Santos - FAC. A festa como vivência do ócio na formação contínua de professores. 2009. Disponível em: <http://www.pucpr.br/eventos/ educere/educere2009/anais/pdf/2730_1449.pdf>. Acesso em: 3 jun. 2014

WORLD LEISURE AND RECREATION ASSOCIATION (WLRA), «international Charter for Leisure Education», Em ELRA (European Leisure and Recreation Association), Verão de 1994, p.13-16. Manuel Cuenca Cabeza, em 2004, apresentou esta Carta em Anexo ao seu livro Pedagogia del Ócio: Modelos y Propuestas. Bilbao. Universidad de Deusto. ISBN: 84-7485-922-0, acrescentando a seguinte informação: Para laedición utilizo latraducción de Yolanda Lázaro Fernández, introduciendoalgunascorrecciones. Fue publicada enGorbeña, S., González, V.J. \& Lázaro, Y. El derecho al ocio de las personas com discapacidad, Universidad de Deusto, Bilbao, 1997, p.243-252. Disponível em: <http://www.eb23-avintes.rcts.pt/avintes/cr/ PDFs/2009_2010/Carta\%20do\%200cio\%20.pdf>. Acesso em: 14 jun. 2014. 
1. Mestre em Educação pela Universidade Tiradentes-SE, bacharel em Direito pela Universidade Tiradentes (Unit-SE), Especialista em Direito Processual Civil pela Associação Educacional Unyahna-BA. Atualmente é professor da Graduação e da Pós Graduação do Curso de Direito da Universidade Tiradentes-SE. E-mail: marltonmota@hotmail.com.

2. Especialista em Direito Tributário pela Universidade Cândido Mendes

(UCAM-RJ), bacharel em Direito pela Universidade Tiradentes (Unit-SE). E-mail: lilianjfmelo@hotmail.com

3. Doutorado em Educação Básica pela Universidade do Vale do Rio dos Sinos - UNISINOS (2004 CAPES - Conceito 6), com bolsa Cnpq na Universidade da Sorbonne-França na área de Educação em Antropologia do Corpo. Possui pós doutorado pela Universidade Complutense de Madrid, na área de filosofia da

Recebido em: 23 de Julho de 2014

Avaliado em: 2 de Fevereiro de 2015 Aceito em: 20 de Maio de 2015
Educação, através de bolsa do Conselho Nacional de Desenvolvimento Científico e Tecnológico, CNpq. É pesquisadora do ITP e professora PPG I da Universidade Tiradentes no Programa de Pós Graduação em Educação. E-mail: dfledens@ hotmail.com 
